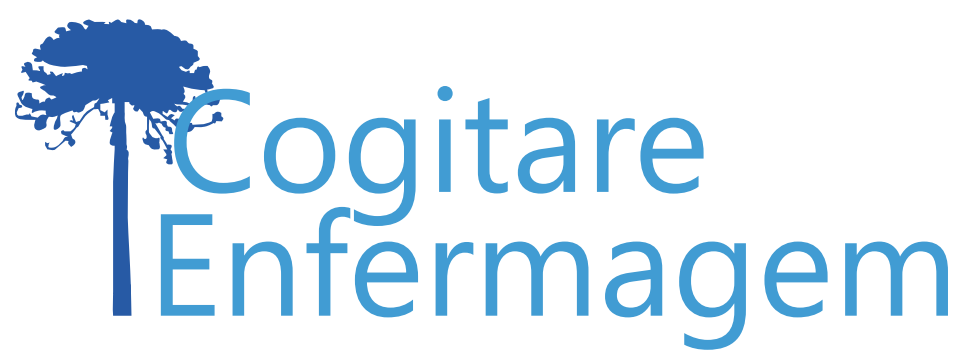

\title{
SENTIMENTOS DE MULHERES ADVINDOS DA EXPERIÊNCIA EM UM PROCESSO DE ABORTAMENTO
}

\author{
Rafael de Castro Santos ${ }^{1}$ (1) \\ Magda Rogéria Pereira Viana ${ }^{2}$ \\ Fernanda Cláudia Miranda Amorim² \\ Marly Marques Rêgo Neta² (1) \\ Kayo Henrique Jardel Feitosa Sousa ${ }^{3}$ (1) \\ Fabiana da Conceição Silva² (1)
}

\section{RESUMO}

Objetivo: conhecer os sentimentos advindos da experiência de mulheres em um processo de abortamento.

Método: estudo qualitativo, desenvolvido em uma maternidade pública de Teresina-PI, entre agosto e setembro de 2018. Participaram 14 mulheres que passaram por abortamento. As categorias emergiram da análise de conteúdo temática.

Resultados: sentimentos surgiram diante da descoberta da gravidez, como a surpresa e o susto por não saberem da gestação até o momento do abortamento. O processo de abortamento trouxe reflexões sobre a situação em que se encontravam. Identificou-se sentimentos como tristeza, medo, desespero, impotência e angústia, além de desconfortos físicos. A pretensão de não engravidar novamente e o desejo de realizar o procedimento de laqueadura foi justificado por estarem desesperançosas e com medo dessa situação se repetir.

Conclusão: conheceram-se sentimentos que mostram que o processo de abortamento é uma vivência complexa e ao mesmo tempo marcada por conflitos psicológicos, caracterizando um evento completamente traumatizante.

DESCRITORES: Aborto; Direitos Sexuais e Reprodutivos; Direitos Humanos; Saúde Pública; Saúde da Mulher.

\section{SENTIMIENTOS DE MUJERES ADVENIDOS DE LA EXPERIENCIA DE UN PROCESO DE ABORTAMIENTO}

\section{RESUMEN:}

Objetivo: conocer los sentimientos advenidos de la experiencia de las mujeres en un proceso de abortamiento. Método: estudio cualitativo, desarrollado en una maternidad pública de Teresina-Pl, entre agosto y septiembre de 2018. Participaron 14 mujeres que se sometieron a un aborto. Las categorías resultaron del análisis de contenido temático. Resultados: surgieron sentimientos frente al descubrimiento del embarazo, como la sorpresa y el susto por no saber del embarazo hasta el momento del aborto. El proceso de abortamiento les hizo reflexionar sobre la situación en la que se encontraban. Se identificó sentimientos como la tristeza, el miedo, la desesperación, la impotencia y la angustia, además del malestar físico. La intención de no volver a quedarse embarazada y el deseo de llevar a cabo un procedimiento de esterilización se justificaba por no tener esperanza y por el miedo a que esta situación vuelva a repetirse. Conclusión: Se conocieron sentimientos que demuestran que el proceso de abortamiento es una vida compleja y al mismo tiempo marcada por conflictos psicológicos, caracterizando un evento completamente traumatizante.

DESCRIPTORES: Aborto; Derechos Sexuales y Reproductivos; Derechos Humanos; Salud Pública; Salud de la Mujer. 
O abortamento é um problema de saúde pública por sua magnitude, persistência e altas taxas de internações devido às complicações ${ }^{(1)}$. Apesar do fortalecimento de políticas de atenção à saúde para as mulheres, em todo o mundo, muitas sociedades ainda desconsideram o processo de abortamento, principalmente em países em desenvolvimento onde as mulheres menos favorecidas são marginalizadas, podendo levar a abortamentos provocados. Embora um número crescente de países tenha conseguido a descriminalização do abortamento, em muitos locais onde tal política ainda não foi possível - como o Brasil -, observa-se aumento dos percentuais de abortamentos inseguros ${ }^{(2)}$.

Dados mundiais mostram que $8 \%$ das mortes de mulheres ocorrem por abortamento inseguro, afetando elas, suas famílias e as futuras gerações ${ }^{(3)}$. Nos seis primeiros meses de 2020, no Brasil, o Sistema Único de Saúde (SUS) realizou 1.024 abortamentos legais e 80.948 curetagens e aspirações (procedimentos para limpeza do útero após abortamento incompleto). Os casos de procedimentos decorrentes de abortamento malsucedidos, provocados ou não, foram 79 vezes mais prevalentes que os legais ${ }^{(4)}$.

As condições socioculturais, legais e subjetivas se relacionam à tomada de decisão quanto ao abortamento e aos sentimentos pós-evento(2). Ao contrário dos estereótipos implantados pelas sociedades, a mulher que aborta é uma mulher "comum", que já é mãe ou poderá se tornar futuramente, de todas as classes e grupos sociais e níveis educacionais ${ }^{(1)}$.

Evidencia-se a opressão, legitimação da violência e desrespeito para com as mulheres menos favorecidas que optam por interromper a gestação e não podem ser atendidas em serviços públicos de saúde, salvo em casos legais de estupro, risco à vida da mulher e comprovação de malformação fetal incompatível com a vida(5).

Apesar de estarem conscientes dos riscos e punições legais contra a realização do abortamento, tais medidas não são suficientes para deixarem de cogitar a interrupção de uma gravidez não planejada. Em contraste, muitas mulheres não apoiam tais práticas até as verem como uma alternativa em meio ao seu desespero, aumentado devido à ilegalidade; todas as mulheres que sofrem abortamento são punidas, mesmo que em diferentes graus e tipos ${ }^{(6-7)}$. Inclusive mulheres que teriam o direito legalizado para a realização do abortamento podem optar pelos meios clandestinos, por não conhecerem seus direitos ou devido ao medo de serem julgadas e não acolhidas $^{(8)}$.

Após vivenciarem o abortamento, as mulheres podem sofrer complicações como hemorragia, sentimentos negativos e incerteza da concretização do abortamento, colocando-as em grande nível de tensão emocional. O estigma e o medo de desrespeito e descuidados pelos próprios profissionais aumentam o risco de morte nessas mulheres, por retardar a procura aos serviços de saúde ${ }^{(9)}$.

Torna-se evidente que, sendo um processo amplo e complexo, o abortamento é um evento singular e permeado de sentimentos pela mulher. Dessarte, conhecer esses sentimentos é primordial para que elas sejam compreendidas e respeitadas pela sociedade e tenham suas necessidades de saúde atendidas pelos profissionais de saúde, mitigando os possíveis danos desse processo. Objetivou-se conhecer os sentimentos advindos da experiência de mulheres em um processo de abortamento. 
Estudo descritivo e qualitativo realizado em uma maternidade pública em TeresinaPI, escolhida por ser uma referência em prestar assistência hospitalar e ambulatorial em casos de abortamento, parto e puerpério.

Foram incluídas no estudo mulheres que passaram pelo processo de abortamento independentemente do tipo, e excluídas aquelas com transtornos psiquiátricos já definidos antes do abortamento. A seleção das participantes ocorreu considerando a disponibilidade e o interesse em participar da pesquisa. Inicialmente, o pesquisador principal dirigiase às chefias das enfermarias questionando se havia mulheres internadas que passaram por abortamento. Para evitar exposição das mulheres diante das demais internadas na mesma enfermaria, em caso afirmativo, buscava-se a confirmação mediante informação no prontuário médico, e só então dirigia-se à mulher. Neste momento apresentava-se a pesquisa, de forma reservada e individual, e questionava-se sobre o interesse em participar.

A coleta dos dados foi realizada entre agosto e setembro de 2018, por meio de entrevistas. Utilizou-se um roteiro semiestruturado, com questões para caracterização das participantes e a seguinte frase disparadora: "Fale livremente sobre sua vivência no processo de abortamento".

As entrevistas foram realizadas na própria instituição, gravadas e transcritas. Para garantia do anonimato das participantes, optou-se por utilizar a inicial " $\mathrm{M}$ ", referente a mulher, seguida por um algarismo arábico, correspondente à ordem de inclusão na pesquisa (M1, ... M14). Para se constatar a saturação teórica, procedeu-se registro dos dados brutos, imersão nos dados, compilação das entrevistas e agrupamento temático, identificação de regularidades e constatação por meio de ausência de novos temas ${ }^{(10)}$.

Os dados foram submetidos à análise de conteúdo temática proposta por Minayo(11), seguindo as etapas: pré-análise (organização e leitura exaustiva do material, em busca de potenciais falas para a análise); exploração do material (leitura minuciosa do corpus textual, a fim de emergirem os núcleos de sentidos, posteriormente agrupados por similitude, para formação das categorias temáticas); e tratamento dos resultados/inferência/interpretação (levantamento das reflexões acerca da temática central, a fim de se propor uma síntese interpretativa subsidiada na produção científica).

Ressalta-se que a não classificação por tipo de abortamento espontâneo ou provocado possa trazer implicações importantes às conclusões levantadas nessa pesquisa, tendo em vista ser um processo permeado por carga sociocultural. No entanto, vale ressaltar que dados demonstram que a maior parte das internações por abortamento são do tipo inseguro ${ }^{(1,4,9)}$ - provocados ou não - que possam ter refletido nos achados e interpretações destes estudo.

Esta pesquisa foi submetida à apreciação de Comitê de Ética em Pesquisa e obteve parecer favorável (n. 2.741.996).

\section{RESULTADOS}

Participaram 14 mulheres com idade entre 20 e 40 anos. Prevaleceu a situação de casada em seis, seguida de união estável (cinco) e solteiras (três); oito declaram-se pardas, três negras, duas brancas e uma mulata. Cinco mulheres relataram ter o ensino fundamental completo, cinco o ensino médio completo, seguidas de duas com ensino fundamental incompleto, uma com ensino superior completo, e outra que tinha o ensino superior incompleto. Seis das entrevistadas exerciam atividade de "dona de casa", três trabalhadoras rurais, duas diaristas, uma secretária, uma monitora escolar e uma professora. Doze das entrevistadas relataram ter renda de até um salário-mínimo, uma possuía de um a três salários-mínimos e outra de quatro a 10 salários-mínimos. 
Tangente aos relatos de suas experiências diante do processo de abortamento, emergiram três categorias temáticas apresentadas a seguir.

\section{Sentimentos diante da descoberta da gravidez}

As participantes relataram as repercussões que a gravidez havia trazido até esse momento, surgindo diversos sentimentos relatados pela maioria diante da descoberta da gravidez, como a surpresa e o susto por não saberem da gestação até o momento do abortamento. Algumas que descobriram o diagnóstico antes relataram os sentimentos de desesperança e felicidade, conforme os depoimentos a seguir:

[...] para mim foi uma surpresa, porque eu não esperava que estava grávida. Eu tava tratando um problema de infecção renal, aí já aos quatro meses eu mais ou menos desconfiei que estava grávida. (M1)

Fiquei surpresa, porque eu não estava esperando a gravidez, não foi planejada. [...] Mas no momento eu não queria. (M2)

Surpresa, porque não sabia que eu tava grávida, vim saber quando dei entrada aqui. Por que tava sangrando muito, quando dei entrada que vim saber que eu tinha abortado um bebê (M3)

Ah, eu tomei um susto, eu era ligada há cinco anos. Fizeram a ligação aqui, disseram que tinham me ligado né?! [...] Aí fui ao banheiro e senti uma dor forte na barriga, senti um negócio como se fosse descer, eu chamei o médico, ele veio me examinar e ele perguntou se eu sabia que eu tava grávida e eu disse que não sabia não, por que minha menstruação descia direitinho, nunca atrasou. [...] ele disse que eu tava grávida, eu tomei susto, minha pressão subiu e me mandaram pra cá. (M4)

Eu fiquei feliz, claro. Qual é a mulher que não fica feliz? Até porque eu já tenho uma filha, e ela ficou muito feliz porque ia receber um irmãozinho. (M6)

\section{Sentimentos frente à experiência do abortamento}

Em relação ao abortamento, relataram sentimentos como tristeza, medo, desespero, impotência e angústia. Esses sentimentos as conduziram a uma autorreflexão sobre a situação vivida. Ainda, surgiram alguns relatos referentes a desconfortos físicos, sobre o qual afirmam como um evento severamente doloroso e sanguinolento, conforme os relatos:

Não foi muito agradável não, porque é uma notícia que deixa a gente mesmo lá embaixo, mas aí tem que tentar se controlar, né? [...] eu tava mais angustiada a princípio [...] o feto já estava morto na barriga. (M1)

Entrei em desespero, porque nunca tinha passado por isso, foi a primeira vez. Eu senti dor no pé da barriga e perdi muito sangue [...] me senti triste, porque queria que tivesse gerado até os noves meses. (M3)

[...] a gente fica triste no momento e pensativa, porque não é o que a gente espera que aconteça, mas infelizmente tem que aceitar e pegar na mão de Deus. (M7)

Já esperava como seria, por que já tinha ocorrido antes, mas mesmo assim foi muito doloroso. Fiquei bem triste, porque queria que fosse até o fim e levar para casa. (M8)

Na hora do abortamento eu sentia muita dor, e eu fiquei muito triste, aí só vi quando me colocaram os remédios e me levaram para a sala. (M9)

Eu me sentia muito mal, pensava que iria morrer, que tava perdendo muito sangue, [...] as pessoas falam que a gente só tem seis litros de sangue e eu via tanto sangue, eu imaginava 
que eu já teria perdido uns cinco, que só tinha um. Pensava muita coisa. (M10)

Só sentia muita dor na hora, não parava de sentir dor. (M12)

Senti dor demais, na barriga. Enquanto não saiu tudo para fora não parou de doer minha barriga. Sangrei demais, ave-maria. (M13)

\section{Sentimentos pelas consequências do abortamento}

Quase em toda sua totalidade, as mulheres relataram a pretensão de não engravidar novamente e o desejo de realizar o procedimento de laqueadura, por estarem desesperançosas e com medo de um novo abortamento. Poucas mulheres pretendiam uma nova gestação, conforme é mostrado nas falas:

[...] eu vou providenciar logo a laqueadura, [...] porque não é mais... não sou mais a mesma, vamos dizer assim, minha idade já avançou. Então eu vou procurar fazer a laqueadura para tentar evitar esse tipo de problema novamente. (M1)

Eu não quero mais engravidar. Eu já tenho um filho, a gravidez não foi planejada, aconteceu. Aí como eu já tenho um filho, eu não quero ter outro. O mundo já tá muito populoso. (M2)

Não pretendo engravidar agora, pretendo me prevenir, ir ao ginecologista e procurar tomar anticoncepcional. (M3)

Na hora que sair daqui pretendo engravidar de novo, mas queria informações sobre isto. (M9)

Acabar meu resguardo e seguir a vida para frente. Vê se faço um encaminhamento aí para me ligar que é melhor. (M14)

\section{DISCUSSÃO}

A descoberta da gravidez, para algumas mulheres entrevistadas, ocorreu durante o processo de abortamento. Revelou-se pelas entrevistas ainda que, em sua maioria, a gravidez não foi planejada e sua descoberta repleta de sentimentos como culpa, vergonha, remorso e outros conflitos emocionais. O desejo de ser mãe é algo também presente nessas mulheres, mas há circunstâncias desfavoráveis nas suas vidas que contrariam esse desejo e as levam a refletir sobre continuar a gravidez ${ }^{(12-13)}$.

A surpresa causada pela gravidez faz essas mulheres se desesperarem por não se sentirem prontas a serem mães e temerem mudanças em sua rotina ${ }^{(5)}$. Isso confirma 0 quanto é importante identificar e reduzir problemas gestacionais ou conflitos causados na vida dessas mulheres, por meio de acompanhamento digno, respeitoso e adequado planejamento familiar.

Embora o comportamento durante a descoberta da gravidez seja provavelmente diferente em casos de abortamentos espontâneos e induzidos, acredita-se que a descoberta precoce da gravidez possa influenciar os abortamentos. Estudo demonstrou redução no uso de medicamentos durante a gravidez após as consultas, devido a maior percepção de danos possíveis ao feto ou da não necessidade do tratamento medicamentoso ${ }^{(14)}$.

Estudo(15) relata que há um enorme conflito nas mulheres causado pela contradição de sentir-se felizes e tristes com a descoberta da gravidez. Na medida em que não desejam a gravidez, sentem-se frustradas e na obrigação de atenderem às expectativas sociais e 
aos valores morais e religiosos da sociedade.

O desejo da mulher pela gravidez geralmente não é produzido de forma individual, mas influenciado também pelas relações afetivo-sexuais e familiares. A aceitação da gravidez por casais em união estável tende a apresentar menos conflitos e o fato de ter ou não parceiro fixo acaba convergindo para diferentes vivências gestacionais ${ }^{(16)}$.

Inicialmente, a trajetória das mulheres durante o processo de abortamento é marcada por diversos obstáculos, imersas pelas desigualdades sociais que culmina na demora em procurar serviços de saúde pela difícil acessibilidade e pelo medo. $O$ medo de não poder ter filhos futuramente é um sentimento que predomina entre as mulheres que ainda não possuem filhos e sofreram um abortamento de forma espontânea. Algo também expresso é a solidão, além do forte sentimento de tristeza devido à perda, o que as envergonham ${ }^{(13,17)}$.

As mulheres que abortam ou estão abortando já chegam às maternidades bastante sensibilizadas, e esse processo é marcado por uma série de eventos. $O$ seu estado psicológico se encontra abalado, além de se sentirem muito mal e com medo, pois não têm explicações sobre o que vai acontecer; e, na maioria das vezes, apresentam de forma acompanhada sintomas como hemorragia e febre ${ }^{(18)}$.

Não há evidências de diferenças nas vivências de mulheres que viveram abortamento induzido comparadas às que viveram abortamento espontâneo, pois a vulnerabilidade e o medo referente ao atendimento, principalmente no serviço público, está presente nos dois tipos. Embora o tratamento se torne diferente caso seja considerada "culpada" pelo ato, na perspectiva dos profissionais ${ }^{(18)}$.

Apesar de não terem planejado a gravidez, parte das mulheres investigadas mostraramse extremamente tristes com a perda do filho. Porém, a conclusão do abortamento trouxe um sentimento de paz, devido ao medo vivenciado durante o momento e estarem passando pela primeira vez por aquela situação - ou até para as que já tinham vivenciado esse processo -, e terem sobrevivido.

A morte é com certeza algo que assusta essas mulheres, em decorrência do conhecimento dos perigos de um abortamento, o que as deixam também angustiadas e "culpadas", podendo evoluir para sintomas depressivos(19). A situação psicológica na qual elas se encontram durante esse processo não pode ser negligenciada, por serem vivenciadas reações negativas bastante intensificadas, que podem ser percebidas ou até presumidas $^{(20)}$.

É importante que nesse momento as mulheres tenham o apoio emocional ideal, principalmente dos profissionais de saúde. Embora cada profissional tenha seus próprios limites no que diz respeito a esse processo, isso não deve influenciar de forma alguma os cuidados garantidos a essa mulher. Os profissionais devem ser preparados para atendê-las e assim não afetar negativamente a qualidade do serviço prestado, proporcionando mais informações para atender melhor às suas necessidades ${ }^{(17)}$.

O sofrimento físico é um dos aspectos que também afetam muito as mulheres durante o processo de abortamento, acompanhado de tonturas e outros sintomas que as fazem procurar atendimento em serviços públicos. Porém esses sintomas (principalmente a dor) geralmente são amplificados durante a realização da curetagem e podem ser sentidos dias depois de sua realização, fragilizando ainda mais essa mulher ${ }^{(12)}$.

Estudo(21) mostrou que à finalização concreta do abortamento, a maioria das mulheres necessita de internações devido a complicações e consequente evacuação uterina, dado reforçado pelo número expressivo de internações e procedimentos relacionados ao

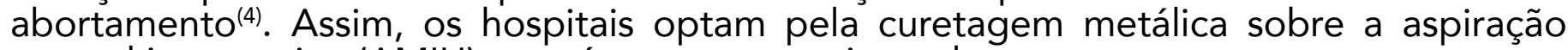
manual intrauterina (AMIU), que é menos agressiva e danosa.

A experiência da dor no abortamento é comumente aliada ao sangramento e à longa 
espera por atendimento devido à prioridade aos partos e gestantes, quando comparado aos cuidados em caso de abortamentos provocados ${ }^{(22)}$. Essa experiência dolorosa pode ser enxergada pelos profissionais como uma forma de não incentivar o abortamento. Esse ato de recusa e/ou de longa espera por atendimento caracteriza-se como violência obstétrica ${ }^{(23)}$.

A percepção da dor é subjetiva, mas seu controle deve ser uma prioridade da equipe que faz o cuidado durante o processo de abortamento. A criação de melhores estratégias de analgesia - não focadas apenas em métodos farmacológicos - é fundamental, proporcionando mais conforto e tranquilidade, para que os medos não se sobressaiam. Quanto maior o medo, mais severa será a dor sentida por essas mulheres ${ }^{(24)}$.

O processo do abortamento traz riscos adicionais, em grande parte por sua estigmatização, e assim se torna um evento sob condições estressantes, aumentando o risco de complicações físicas e psicológicas e de impacto na saúde pública ${ }^{(25)}$. Estudo(26) associa que o abortamento pode aumentar o risco de câncer de mama em mulheres nulíparas. Ainda, mulheres que tiveram abortamento no primeiro trimestre podem apresentar transtornos mentais elevados tanto quanto as que abortaram de forma tardia, algo que se difere muito devido às suas vivências ${ }^{(27)}$.

Os transtornos psiquiátricos podem estar presentes após o abortamento, relacionados principalmente por uma vivência negativa desse processo, embora também existam outros indicadores que elevam os riscos do aparecimento desses transtornos e devem ser levados em consideração, como quando provêm de uma gestação em um relacionamento instável(28).

Por ser um evento traumatizante, muitas das mulheres podem sofrer de baixa autoestima e desesperança, e por vezes, levá-las a sentimentos de não querer mais engravidar. Assim, pesquisa ${ }^{(29)}$ recomenda que essas mulheres sejam mantidas juntas, visando comunicação e troca de experiências que podem ser importantes para o enfrentamento dessa situação.

A forma como as mulheres são cuidadas nos serviços de saúde, em particular por profissionais com valores cristãos, possui potencial repercussão no desejo de engravidar novamente após um abortamento. Estudo ${ }^{(30)} \mathrm{com}$ profissionais de enfermagem evidenciou que comportamentos discriminatórios interferem na assistência, que acaba por ser focada somente em aspectos clínicos.

Após passarem pelo processo de abortamento, as mulheres geralmente não recebem muitas orientações e nenhum tipo de recomendação sobre os cuidados que precisam ter e as alternativas para realização de escolhas saudáveis pós-abortamento. Em regiões onde há sistemas de saúde que proporcionam melhor acesso, todos os tipos de cuidados são feitos para tratar complicações antes que elas ocorram.

Na maioria das vezes, também não há um retorno para o controle de eventuais problemas $^{(7)}$. Existe uma associação positiva entre abortamentos seguros e leis menos restritas, que promove mais profissionais treinados e ambientes propícios para isso(3). A falta de serviços para atenção pós-abortamento de qualidade e um adequado planejamento familiar afetam maiores números de gestações não planejadas e de abortamentos, constituindo-se assim um loop infinito nesse processo ${ }^{(8)}$.

Cabe ressaltar que este estudo, ao seguir sem distinção dos tipos de abortamento, justificado pela ilegalidade e o medo das mulheres em relatarem suas experiências dentro do ambiente de serviços públicos, pode apresentar pequenas diferenças nos resultados, caracterizando-se como limitação e possibilidade de continuação de estudos. 
Conheceram-se sentimentos que mostram que o processo de abortamento é uma vivência por vezes complexa e, ao mesmo tempo, marcada por conflitos psicológicos, caracterizando um evento traumatizante e solitário. Esse fato é acompanhado de grande sofrimento físico, o que pode causar desesperança diante de nova gravidez, além de possível evolução para danos psicológicos.

Desvelar os sentimentos dessas mulheres soma para ampliar a compreensão sobre o problema. Dessarte, vislumbram-se possibilidades de intervenções de enfermagem específicas para mitigar os danos emocionais decorrentes desse processo, expressos por meio dos sentimentos identificados neste estudo. Além disso, traz luz a um fenômeno pouco investigado e que envolve um contexto sociocultural amplo a ser considerado no bojo das políticas de saúde pública e nos planejamentos assistenciais dos serviços de enfermagem.

\section{REFERÊNCIAS}

1. Diniz D, Medeiros M, Madeiro A. National Abortion Survey 2016. Cienc. saúde coletiva. [Internet]. 2017 [acesso em 16 out 2018]; 22(2). Disponível em: http://dx.doi.org/10.1590/1413-81232017222.23812016.

2. World Health Organization (WHO). Trends in maternal mortality: 1990 to 2015. [Internet]. Geneva: WHO; 2015 [acesso em 15 maio 2019]. Disponível em: http://apps.who.int/iris/ bitstream/10665/194254/1/9789241565141 eng.pdf?ua=1.

3. Ganatra B, Gerdts C, Rossier C, Johnson Jr BR, Tunçalp O, Assifi A, et al. Global, regional, and subregional classification of abortions by safety, 2010-14: estimates from a Bayesian hierarchical model. Lancet [Internet]. 2017 [acesso em 19 maio 2019]; 390(10110). Disponível em: http://dx.doi.org/10.1016/ S0140-6736(17)31794-4.

4. Ministério da Saúde (BR). Informações de Saúde [Internet]. 2020 [acesso em 12 dez 2020]. Disponível em: https://datasus.saude.gov.br/informacoes-de-saude-tabnet/.

5. Santos CS, Silveira LMC da. Perceptions related to the autonomy of the female body by women who had Abortions. Psicol. cienc. prof. [Internet]. 2017 [acesso em 17 maio 2019]; 37(2). Disponível em: http:// dx.doi.org/10.1590/1982-3703000582016.

6. Chigbu CC, Chigbu CO, Iwuji SE, Emenalo FC, Onyebuchi AK. Impact of abortion laws on women's choice of abortion service providers and facilities in southeastern Nigeria. Niger J Clin Pract [Internet]. 2018 [acesso em 19 maio 2019]; 21(9). Disponível em: https://www.ncbi.nlm.nih.gov/pubmed/30156194.

7. Silveira P, McCallum C, Menezes G. Personal experiences with induced abortions in private clinics in Northeast Brazil. Cad. Saúde Pública [Internet]. 2016 [acesso em 19 maio 2019]; 32(2). Disponível em: http://dx.doi.org/10.1590/0102-311x00004815.

8. Giugliani C, Ruschel AE, Silva MCB da, Maia MN, Oliveira DOPS de. The right to abortion in Brazil and the role of Primary Health Care. Rev Bras Med Fam Comunidade. [Internet]. 2019 [acesso em 21 maio 2019]; 14(41). Disponível em: http://dx.doi.org/10.5712/rbmfc14(41)1791.

9. Duarte NIG, Moraes LL de, Andrade CB. Abortion experience in the media: analysis of abortive paths shared in an online community. Ciênc. saúde coletiva [Internet]. 2018 [acesso em 21 maio 2019]; 23(10). Disponível em: http://dx.doi.org/10.1590/1413-812320182310.14062018.

10. Fontanella BJB, Luchesi BM, Saidel MGB, Ricas J, Turato ER, Melo DG. Amostragem em pesquisas qualitativas: proposta de procedimentos para constatar saturação teórica. Cad. Saúde Pública [Internet]. 2011 [acesso em 16 out 2018]; 27(2). Disponível em: https://doi.org/10.1590/S0102-311X2011000200020.

11. Minayo MCS. Pesquisa social: teoria, método e criatividade - Série Manuais Acadêmicos. Rio de 
Janeiro: Vozes; 2016.

12. Porto RM, Sousa CHD. "Treading Pathways of Anguish": Abortion Itineraries in a Brazilian Northeastern Capital. Rev. Estud. Fem. [Internet]. 2017 [acesso em 27 out 2018]; 25(2). Disponível em: http://dx.doi.org/10.1590/1806-9584.2017v25n2p593.

13. Ditzhuijzen Van J, Brauer M, Boeije H, Nijnatten Van CHCJ. Dimensions of decision difficulty in women's decision-making about abortion: a mixed methods longitudinal study. Plos One [Internet]. 2019 [acesso em 25 maio 2019]; 14(2). Disponível em: http://dx.doi.org/10.1371/journal.pone.0212611.

14. Leong C, Chateau D, Dahl M, Falk J, Katz A, Bugden S, et al. Prescription medication use during pregnancies that resulted in births and abortions (2001-2013): a retrospective population-based study in a Canadian population. Plos One [Internet]. 2019 [acesso em 25 maio 2019]; 14(3). Disponível em: http:// dx.doi.org/10.1371/journal.pone.0211319.

15. Machado CL, Fernandes AM dos S, Osis MJD, Makuch MY. Rape-related pregnancy in Brazil: the experience of women seeking legal abortion. Cad. Saúde Pública [Internet]. 2015 [acesso em 28 out 2018]; 31(2). Disponível em: http://dx.doi.org/10.1590/0102-311X00051714.

16. Milanez N, Oliveira AE, Barroso ADV, Martinelli KG, Esposti CDD, Santos Neto ET dos. Unwanted pregnancy and abortion attempt: practices and contexts. Sex., Salud Soc [Internet]. 2016 [acesso em 27 out 2018]; 22. Disponível em: http://dx.doi.org/10.1590/1984-6487.sess.2016.22.06.a.

17. Cárdenas R, Labandera A, Baum SE, Chiribao F, Leus I, Avondet $S$, et al. "It's something that marks you": abortion stigma after decriminalization in Uruguay. Reproductive health [Internet]. 2018 [acesso em 28 maio 2019]; 15(150). Disponível em: http://dx.doi.org/10.1186/s12978-018-0597-1.

18. Goes EF, Menezes GMS, Almeida MCC, Araújo TVB de, Alves SV, Alves MTSSB e, et al. Racial vulnerability and individual barriers for Brazilian women seeking first care following abortion. Cad. Saúde Pública [Internet]. 2020 [acesso em 10 mar 2020]; 36(supl.1). Disponível em: https://doi.org/10.1590/0102311x00189618.

19. Beraldo A, Birchal T de S, Mayorga C. Induced Abortion: a study on women's experiences. Rev. Estud. Fem. [Internet]. 2017 [acesso em 29 maio 2019]; 25(3). Disponível em: http://dx.doi.org/10.1590/18069584.2017v25n3p1141.

20. Adesse L, Jannotti CB, Silva KS da, Fonseca VM. Abortion and stigma: an analysis of the scientific literature on the theme. Cienc. saúde coletiva [Internet]. 2016 [acesso em 03 nov 2018]; 21(12). Disponível em: http://dx.doi.org/10.1590/1413-812320152112.07282015.

21. Melese T, Habte D, Tsima BM, Mogobe KD, Nassali MN. Management of post abortion complications in Botswana -The need for a standardized approach. Plos One [Internet]. 2018 [acesso em 29 maio 2019]; 13(2). Disponível em: http://dx.doi.org/10.1371/journal.pone.0192438.

22. Madeiro AP, Rufino AC. Maltreatment and discrimination in induced abortion care: perception of women in Teresina, State of Piauí, Brazil. Ciênc. saúde coletiva [Internet]. 2017 [acesso em 03 nov 2018]; 22(8). Disponível em: http://dx.doi.org/10.1590/1413-81232017228.04252016.

23. Leal MARF, Castelar M. Abortion in adolescence: practice of psychologists in public maternity hospitals in Salvador, Bahia. Psicol. cienc. prof. [Internet]. 2019 [acesso em 29 maio 2019]; 39. Disponível em: http://dx.doi.org/10.1590/1982-3703003178707.

24. Duros S, Joueidi Y, Timoh KN, Boyer L, Lemeut $P$, Tavenard A, et al. A prospective study of the frequency of severe pain and predictive factors in women undergoing first-trimester surgical abortion under local anaesthesia. Eur J Obstet Gynecol Reprod Biol [Internet]. 2018 [acesso em 30 maio 2019]; 221. Disponível em: http://dx.doi.org/10.1016/j.ejogrb.2017.12.024.

25. Sedgh G, Filippi V, Owolabi OO, Singh SD, Askew I, Bankole A, et al. Insights from an expert group meeting on the definition and measurement of unsafe abortion. Int J Gynaecol Obstet [Internet]. 2016 [acesso em 04 nov 2018]; 134(1). Disponível em: http://dx.doi.org/10.1016/j.ijgo.2015.11.017. 
26. Deng $Y, X u H$, Zeng $X$. Induced abortion and breast cancer: an updated meta-analysis. Medicine [Internet]. 2018 [acesso em 01 jun 2019]; 97(3). Disponível em: https://pubmed.ncbi.nlm.nih. gov/29504989/.

27. Biggs MA, Neuhaus JM, Foster DG. Mental health diagnoses 3 Years after receiving or being denied an abortion in the United States. Am J Public Health [Internet]. 2015 [acesso em 01 jun 2019]; 105(12). Disponível em: http://dx.doi.org/10.2105/AJPH.2015.302803.

28. Ditzhuijzen Van J, Have M ten, Graaf R de, Nijnatten CH van. Vollebergh WAM. Correlates of common mental disorders among dutch women who have had an abortion: a longitudinal cohort study. Perspect Sex Repro H [Internet]. 2017 [acesso em 02 jun 2019]; 49(2). Disponível em: http://dx.doi.org/10.1363/ psrh.12028.

29. Kamranpour B, Noroozi M, Bahrami M. Supportive needs of women who have experienced pregnancy termination due to fetal abnormalities: a qualitative study from the perspective of women, men and healthcare providers in Iran. BMC Public Health [Internet]. 2019 [acesso em 02 jun 2019]; 19(507). Disponível em: http://dx.doi.org/10.1186/s12889-019-6851-9.

30. Strefling I da SS, Lunardi Filho WD, Kerber NP da C, Soares MC, Ribeiro JP. Nursing perceptions about abortion management and care: a qualitative study. Texto contexto - enferm [Internet]. 2015 [acesso em 28 jun 2019]; 24(3). Disponível em: http://dx.doi.org/10.1590/0104-07072015000940014.

\section{COMO REFERENCIAR ESTE ARTIGO:}

Santos R de C, Viana MRP, Amorim FCM, Rêgo Neta MM, Feitosa Sousa KHJF, Silva F da C. Sentimentos de mulheres advindos da experiência em um processo de abortamento. Cogitare enferm. [Internet]. 2021 [acesso em "colocar data de acesso, dia, mês abreviado e ano"]; 26. Disponível em: http://dx.doi.org/10.5380/ce.v26i0.72376.

Recebido em: 21/03/2020

Aprovado em: 21/12/2020

Editora associada: Tatiane Herreira Trigueiro

Autor Correspondente:

Rafael de Castro Santos

Centro Universitário Uninovafapi - Teresina, PI, Brasil

E-mail: rafaelcastrork@gmail.com

Contribuição dos autores:

Contribuições substanciais para a concepção ou desenho do estudo; ou a aquisição, análise ou interpretação de dados do estudo - RCS, MRPV, FCMA, MMRN, KHJFS, FCS

Elaboração e revisão crítica do conteúdo intelectual do estudo - RCS, MRPV, FCMA, MMRN, KHJFS, FCS

Aprovação da versão final do estudo a ser publicado - RCS, MRPV, FCMA, MMRN, KHJFS, FCS

Responsável por todos os aspectos do estudo, assegurando as questões de precisão ou integridade de qualquer parte do estudo - RCS, MRPV, FCMA, MMRN, KHJFS, FCS

Copyright @ 2021 Este é um artigo em acesso aberto distribuído nos termos da Licença Creative Commons Atribuição, que permite o uso irrestrito, a distribuição e reprodução em qualquer meio desde que o artigo original seja devidamente citado. 